\title{
Soil surface albedo and multispectral reflectance of short-wave radiation as a function of degree of soil slaking
}

\author{
G. van der Heide and A.J. Koolen
}

Tillage Laboratory, Agricultural University, Diedenweg 20, Wageningen, the $\mathrm{Ne}$ therlands

Accepted: 25 September 1980

Key words: remote sensing, soil slaking, spectral reflection

\section{Summary}

Soil slaking is an undesired phenomenon, which may lower crop yields. Slaking varies with time and from one place to another. Mapping feasibility of the degree of soil slaking for the case of remote sensing on the basis of reflected solar radiation was investigated through measuring spectral reflection curves in laboratory experiments. Slaking affected the level, but not the shape of the spectral curves.

\section{Introduction}

Soil may slake due to rainfall. Slaking is a process of soil particles at the surface being moved by rainwater and deposited in hollows. It may result in the formation of a dense toplayer in the soil, which can have a bad influence on the heat, air and moisture regimes in the soil. This may lower crop yields. Because degree of soil slaking may vary with time and from one place to another, it must be advantageous when slaked soils could be mapped easily.

We investigated mapping feasibility of degree of soil slaking for the case of remote sensing on the basis of reflected solar radiation. Soil was slaked under controlled conditions in the laboratory, after which spectral reflection of the soil surface irradiated by lamps was determined.

\section{Experimental techniques and procedures}

Because

- degree of soil slaking mainly depends on amount of rainfall;

- wave lengths of sunlight are much smaller than surface irregularities induced by tillage;

the situation in agricultural practice can be simulated by 
- a shortlasting experiment in which high amounts of rainfall are applied by a rain simulator;

- a 'scaled' soil surface of relatively small dimensions.

The rain simulator. Its purpose was to make artificial rainfall having a very realistic appearance, with the possibility of adjusting intensity and duration of the rainfall. The size of the soil samples needed a large rain simulator. The type used is constructed by Technische en Fysische Dienst voor de Landbouw in Wageningen according to a design of Morin, Goldberg \& Seginer (1966). In this apparatus, water under pressure is distributed over the test surface through a nozzle at a height of $2 \mathrm{~m}$ above the soil sample. In the experiments rain intensity was maintained at $32 \mathrm{~mm} / \mathrm{h}$.

The spectrometer used was developed by Technisch-Physische Dienst TNO-TH in Delft. Its principle of operation was that radiations reflected by a test object and by a reference reflector (from which the reflection coefficient was known) were measured simultaneously (Anon., 1977). The two radiation beams entering the apparatus were dispersed by a grating. The dispersed light from object and reference was lead to three sensors which transformed the light intensities into electrical signals. Through electronic amplifying, forming the ratio of the signals and taking into account the necessary calibrations, the reflection coefficient was calculated as a function of the wavelength for the $361-2360 \mathrm{~nm}$ wavelength range. The output signals of the spectrometer were recorded on a three-channel pen recorder as well as on magnetic tape, allowing data processing by computer.

The experimental set-up. The geometry of the set-up was maintained as constant as possible, enabling us to measure reflections under identical conditions through-

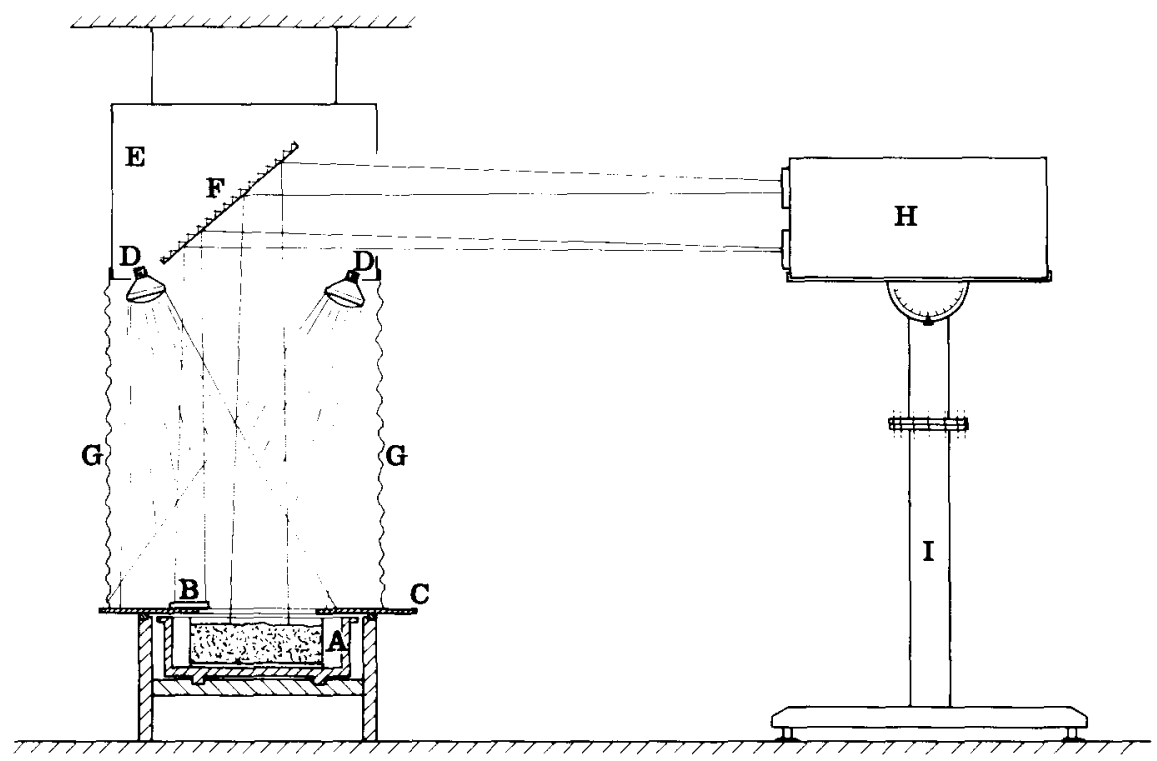

Fig. 1. Experimental set-up. 
out the experimental period. Fig. 1 gives a scheme. Both the soil in test bin A and the reference-reflector $B$ on top plate $C$ were irradiated by light from the lamps D. The reflected radiation of both objects was supplied to the spectrometer $\mathrm{H}$ via mirror $F$. Screens $E$ and $G$ were used to avoid light from the outside. The test bin consisted of a plastic outer bin $\left(60 \times 40 \times 20 \mathrm{~cm}^{3}\right)$, in which an inner bin made out of perforated sheet was mounted. When the soil in the inner bin was rained on, part of the rainwater infiltrated into the soil and drained away via the perforated bottom, the rest running off over the soil surface and through the side walls.

The measuring program. The measurements were done on aggregates smaller than $5 \mathrm{~mm}$ diameter from Oudelande sandy loam soil $(\mathrm{pH} \mathrm{KCl}=0.074$, organic matter content $=0.16 \mathrm{~g} / \mathrm{kg}$ soil, $\mathrm{CaCo}_{3}$ content $=42 \mathrm{~g} / \mathrm{kg}$ soil. This soil is very sensitive to slaking. Test bins were filled with a constant amount of soil, and then ploughed at a 1/3rd scale of ploughing under practical conditions, using a spatula. (It was assumed that scale of the surface relief did not affect reflection properties.) Four bins were prepared and a measuring series was taken from each bin. These series were labelled $\mathrm{A}, \mathrm{B}, \mathrm{C}$ and $\mathrm{D}$. The starting and end conditions were respectively:

A) saturated, not slaked $\rightarrow$ air-dry, not slaked

B) saturated, fully slaked $\rightarrow$ air-dry, fully slaked

C) air dry, not slaked $\rightarrow$ air-dry, not slaked

D) saturated, not slaked $\rightarrow$ saturated, fully slaked

Between the starting and end conditions, A and B were allowed to dry gradually, C was kept constant, and D was gradually slaked. Slaking in D was obtained by raining once a day at the same hour during a 6-day period. Rain duration varied; on the first day rain was applied during 6 minutes; on the remaining 5 days always during 30 minutes. On the sixth day the soil surface became totally slaked. Then, $D$ had received $83.2 \mathrm{~mm}$ rainfall in total! Reflection was measured at regular intervals between the starting and end conditions for each series. In addition, moisture content of the top few mm's was determined at each reflection measurement. The measurements in D were always done just prior to each raining, so that water on the soil surface had the opportunity to sink away for a whole day before measurement.

Series $\mathrm{C}$ was planned to get an idea of the scatter of the reflection measurements; the reflection values were expected to be unchanged when moisture content did not change.

The measurements on the bins extended over 20 days.

\section{Results and discussion}

For each series, curves at several moisture contents were obtained, in which soil surface reflection is plotted against wavelength. Fig. 2 presents a number of such curves. For the sake of clarity, only the lowest and highest curves within each series have been drawn. Moisture contents at which these curves were measured are presented by the numbers at the curves. (In this report, all moisture contents are expressed as a percentage by weight.)

Essentially, remote sensing involves energy measurements of reflected solar radia- 


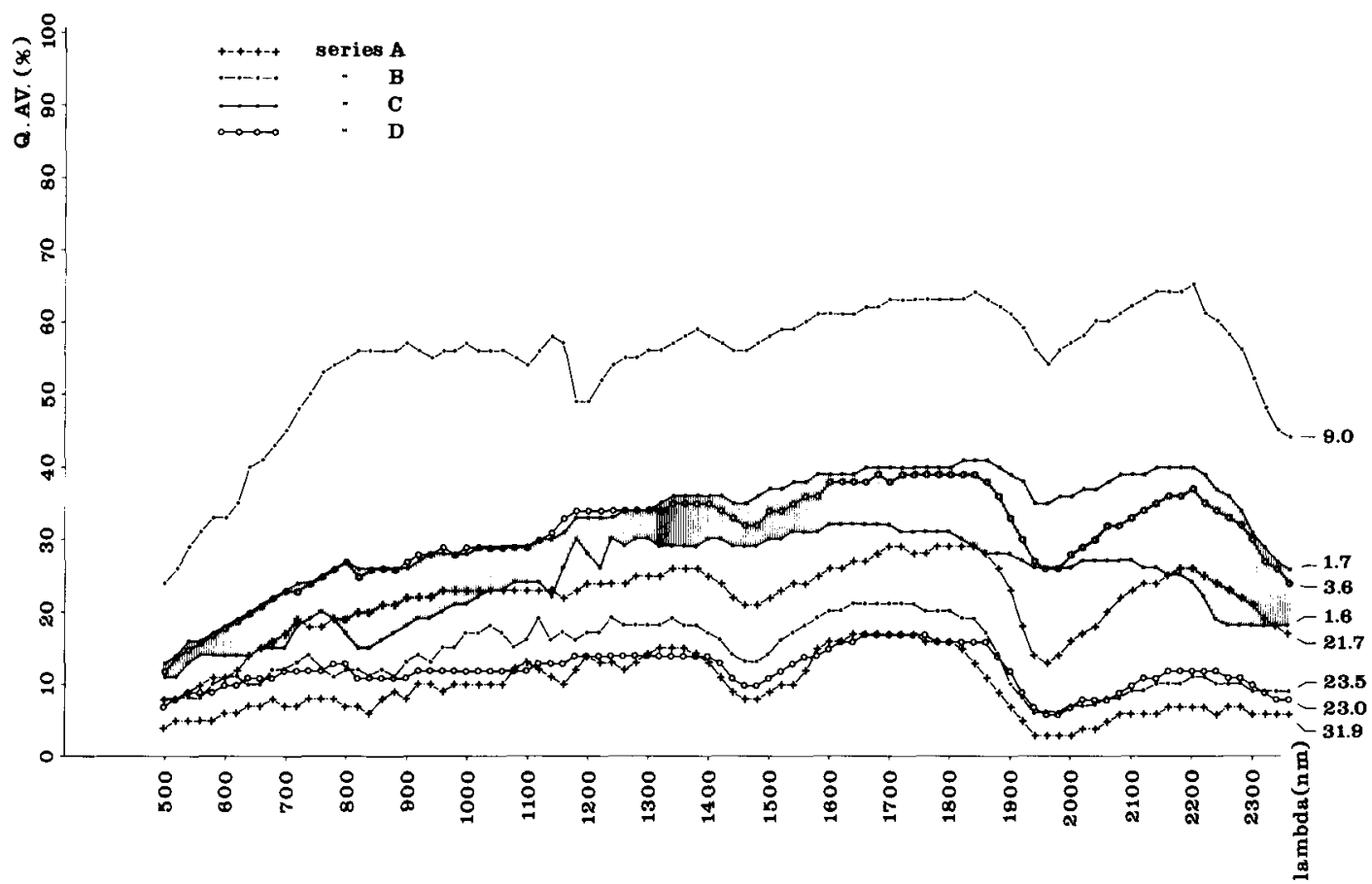

Fig. 2. Reflectivity-wavelength relations for different soil moisture contents and degrees of soil slaking.

tion and therefore, the measured reflection values were transformed into radiation energies applying to a summer day with a clear sky.

The following formula has been used (List, 1951):

$$
\mathrm{E}(\lambda)=\mathrm{c} \times \mathrm{k}(\lambda) \times \mathrm{SE}(\lambda) \times \mathrm{Q}(\lambda)
$$

in which:

$\mathrm{E}(\lambda) \quad=$ reflected energy $\left(\mathrm{W} / \mathrm{m}^{2}\right)$

$c \quad=$ a constant

$\mathrm{k}(\lambda)=$ transmission coefficient of radiation through the atmosphere when the sky is clear

$\mathrm{SE}(\lambda)=$ solar energy outside the atmosphere $\left(\mathrm{W} / \mathrm{m}^{2}\right)$

$\mathrm{Q}(\lambda) \quad=$ the measured reflection coefficient

In this way, Fig. 3 was obtained from the curves of Fig. 2.

To obtain one overall reflection characteristic for each situation, albedos for the total incident solar energy were calculated (soil surface albedo $=$ ratio of reflected to total solar radiation):

$$
\text { albedo }=\frac{\sum(\mathrm{c} \times \mathrm{k}(\lambda) \times \mathrm{SE}(\lambda) \times \mathrm{Q}(\lambda))}{\sum(\mathrm{c} \times \mathrm{k}(\lambda) \times \mathrm{SE}(\lambda))} \times 100(\%)
$$




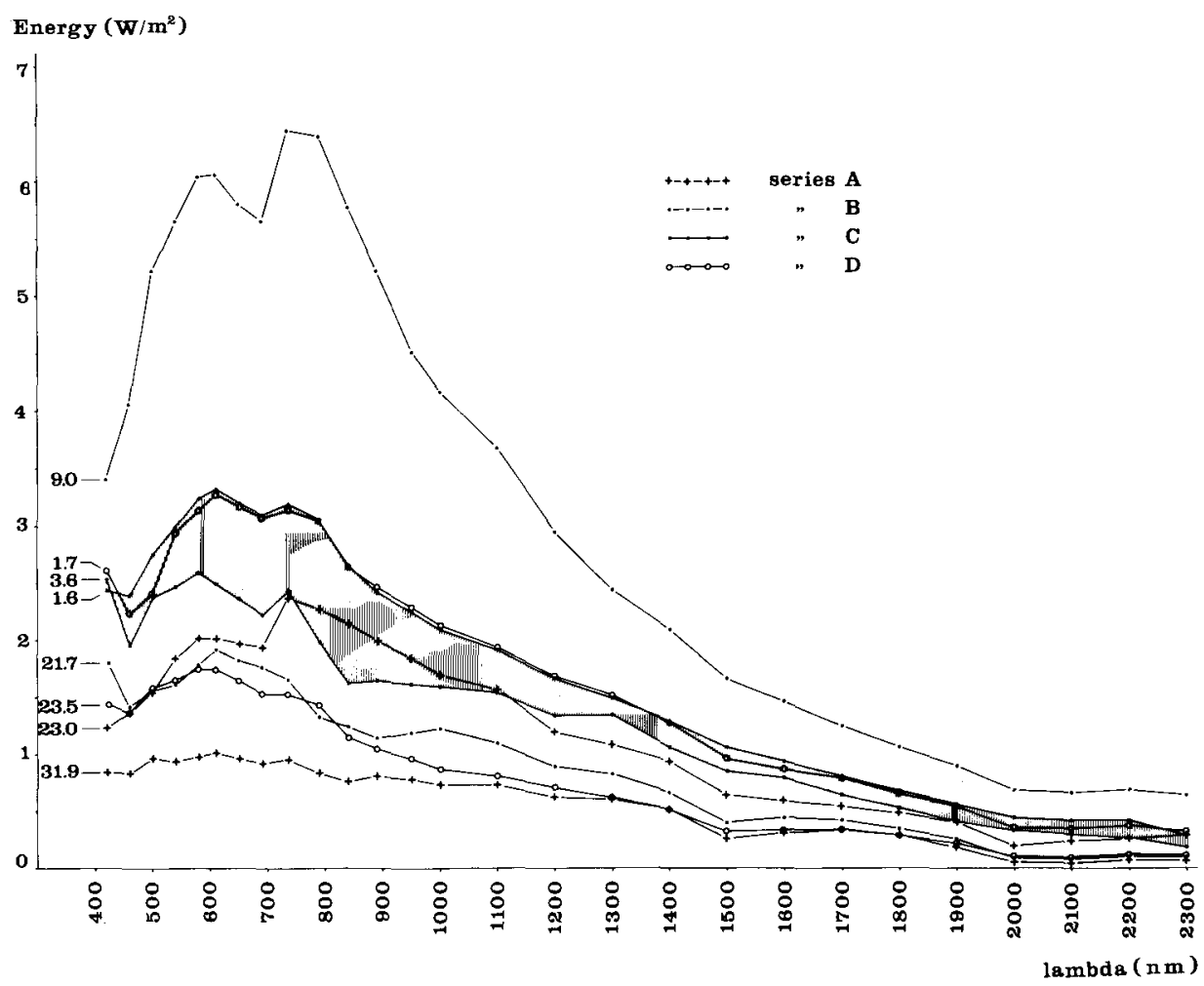

Fig. 3. Reflected solar energy-wavelength relations for different soil moisture contents and degrees of soil slaking.

For each series, albedo is plotted against moisture content prevailing at its measurement in Fig. 4. When the graphs of this graph would be placed side by side in the order C-A-D-B, one would obtain an impression of soil surface albedo variation that will occur when soil is air-dry for a while, then gradually saturated, thereafter gradually slaked due to subsequent rains, and, finally, is slowly dried out in the fully slaked condition ( 1 = air-dry; 2 = saturated, unslaked; 3 = saturated, fully slaked; 4 = air-dry, fully slaked).

Fig. 2 and 3 show the large diversity in the reflections within the series (data scatter is demonstrated by the curves for $\mathrm{C}$ ). It appears that moisture content variations are very little reflected in curve shape, but have a significant influence on curve level. Reflection tends to increase when moisture content decreases. This is confirmed by literature (Bowers \& Hanks, 1965). Also degree of soil slaking has an influence on curve level, but not much on curve shape. It seems that slaking does not much affect reflection (albedo) at high moisture contents (see Fig. 4, series D), and that slaking does affect albedo at lower moisture contents (compare the left part of $A$ with the right part of B).

Because data scatter may be large ( $\mathrm{C}$ in Fig. 2 and 3 ) and curve shape is rather in- 
SOIL SURFACE ALBEDO AND MULTISPECTRAL REFLECTANCE OF RADIATION
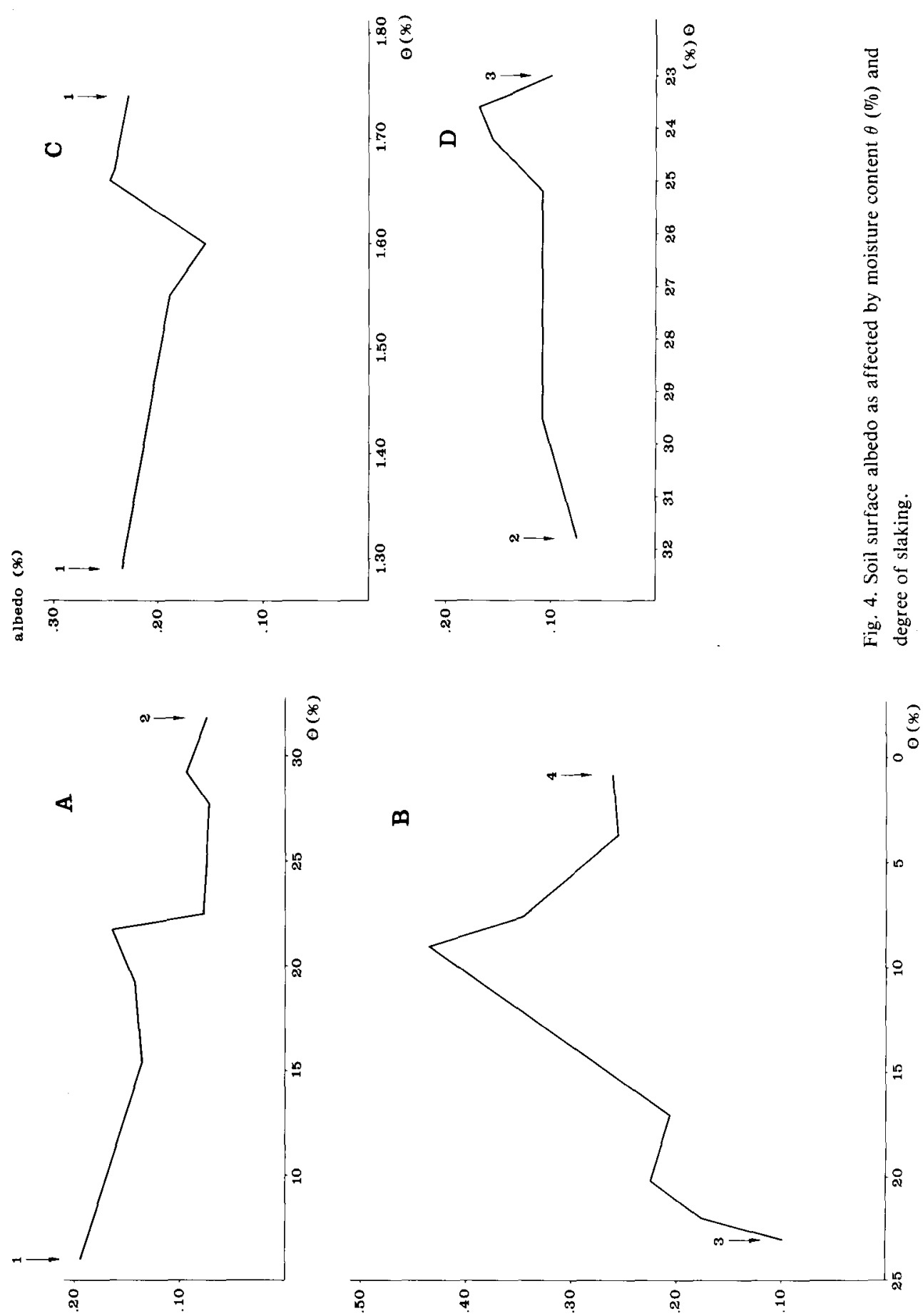

Neth. J. agric. Sci. 28 (1980)

257 
sensitive to slaking, slaking detection on the basis of spectral analysis cannot be recommended. When slaking is to be detected on the basis of reflected solar radiation, detection techniques based on albedo measurements may be successful under dry conditions. It should be noted that slaking will influence soil moisture content, and, therefore, techniques that are sensitive to soil moisture content may also be of use.

\section{References}

Anonymus, 1977. Final Report of the Stuurgroep van het beleidsruimteproject NIWARS. Delft, Netherlands, pp. 44-47.

Bowers, S. A. \& R. J. Hanks, 1965. Reflection of radiant energy from soils, Soil Sci. 100: 130-138.

List, Robert J., 1951. Smithonian meteorological tables, Vol. 114. Smithonian Institution, Washington, pp. 416-431.

Morin, Goldberg \& Seginer, 1966. A rainfall simulator with improved characteristics. Research Report No 14 (May 1966), Israel Ministry of Agriculture.

Reginato, R. J. et al., 1977. An evaluation of total solar reflectance and spectral band rationing techniques for estimating soil water content. J. geophys. Res. 82: 2101-2104. 